\title{
Nonrandom Sampling
}

National Cancer Institute

\section{Source}

National Cancer Institute. Nonrandom Sampling. NCI Thesaurus. Code C71502.

Any method of selecting a sample in which cases are not chosen by random sampling. 